\title{
Processos de tratamento do chorume e reaproveitamento: Uma revisão
}

\author{
Márcia Cristina de Sousa*(Graduanda em Eng. Química pela Universidade Federal de Campina Grande-UFCG). \\ Deborah Almeida dos Anjos (Mestranda em Eng. Química pela Universidade Federal de Campina Grande-UFCG) \\ Emanuele Montenegro Sales (Doutoranda em Eng. Química pela Universidade Federal de Campina Grande-UFCG) \\ Maria Rosiane de A. Andrade (Graduanda em Eng. Química pela Universidade Federal de Campina Grande-UFCG) \\ *Email:marciacrissousa@hotmail.com
}

\section{Resumo:}

Com alto índice de poluentes em sua composição o chorume se destaca em seus tratamento baseados nas normas dos resíduos sólidos das políticas ambientais. Estas que regulam índices de águas de descarte e de liberação de gases na atmosfera.

Conforme a NBR no 10.004, da Associação Brasileira de Normas Técnicas - ABNT - "Resíduos nos estados sólido e semi-sólido, que resultam de atividades da comunidade de origem: industrial, doméstica, hospitalar, comercial, agrícola, de serviços e de varrição. Ficam incluídos nesta definição os lodos provenientes de sistemas de tratamento de água, aqueles gerados em equipamentos e instalações de controle de poluição, bem como determinados líquidos cujas particularidades tornem inviável seu lançamento na rede pública de esgotos ou corpos d'água, ou exijam para isso soluções técnica e economicamente inviáveis, em face à melhor tecnologia disponível".

Chorume é o nome popular dado para o líquido escuro gerado em lixões ou aterros sanitários, em decorrência da percolação das águas de chuva pela massa de lixo. O impacto ambiental deste líquido está relacionado, sobretudo, à alta concentração de matéria orgânica em decomposição, que demanda uma grande quantidade de oxigênio, retirado do meio que ele atingir, ou em que for lançado. $O$ tratamento do chorume pode ser realizado de forma tradicional por uma ETE (a qual engloba gradeamentos, elevatória, caixa de areia, lagoas aeradas, secagem e tratamento do lodo), ou por meios alternativos como separação por membranas; evaporação; tratamentos oxidativos; carvão ativado; eletrocoagulação, etc. $\mathrm{O}$ reaproveitamento do chorume durante o processo é enfoque na sustentabilidade do meio ambiente, neste trabalho irá abranger a geração de biogás, de crédito de carbono, de adubo, de água de reuso.

O tratamento do chorume tem a Sustentabilidade como vertente, tendo em vista um sistema ambientalmente equilibrado, onde irá atender a sociedade de forma justa e econômica. O tratamento do chorume irá acarretar na reciclagem das águas, lodo e gases, como também na não degradação do meio ambiente, promovendo suprir as necessidades atuais da população sem comprometer as futuras gerações.

\section{Palavras-chave:}

Chorume; Tratamento; Reaproveitamento; Sustentabilidade. 


\section{I ntrodução}

Segundo a NBR no 10.004(ABNT) "Resíduos nos estados sólido e semi-sólido, que resultam de atividades da comunidade de origem: industrial, doméstica, hospitalar, comercial, agrícola, de serviços e de varrição. Ficam incluídos nesta definição os lodos provenientes de sistemas de tratamento de água, aqueles gerados em equipamentos e instalações de controle de poluição, bem como determinados líquidos cujas particularidades tornem inviável seu lançamento na rede pública de esgotos ou corpos d'água, ou exijam para isso soluções técnica e economicamente inviáveis, em face à melhor tecnologia disponível".

O chorume se enquadra nestes resíduos devido a sua geração ser em lixões ou aterros sanitários, em decorrência da percolação das águas de chuva pela massa de lixo. Este líquido causa um grande impacto ambiental, devido à alta concentração de matéria orgânica em decomposição, que demanda uma grande quantidade de oxigênio, retirado do meio que ele atingir, que pode prejudicar a fauna e flora aquática. Outros poluentes no chorume são os metais, que podem se apresentar em diversas formas (livres, complexados, não solubilizados). Esses poluentes tem maior rigor nas legislações tendo em vista sua toxicidade ao ambiente.

Rocca (ROCCA, 2010) comentou que o esgoto sanitário, por exemplo, apresenta uma DBO da ordem de $300 \mathrm{mg} / \mathrm{litro}$, enquanto que a DBO do chorume vai de 3.000 a $17.000 \mathrm{mg} / \mathrm{litro}$. O chorume apresenta ainda concentrações de metais pesados e substâncias tóxicas. O descarte do chorume num corpo de água gera depleção de oxigênio, causando impactos como a mortandade de peixes e deixando a água imprópria para os usos a que se destina.

As características gerais do chorume são: concentração de matéria orgânica elevada; recalcitrância aos processos biológicos de tratamento; nitrogênio amoniacal; sais; toxicidade aos organismos aquáticos.

Os parâmetros permitidos para tratamento e descarte do efluente (resíduo chorume) são determinados pelo decreto $\mathrm{N}^{\circ} 8.468$ no art 19-A. A temperatura tem que ser no máximo $40^{\circ} \mathrm{C}$; o $\mathrm{pH}$ do efluente tratado deve ter em torno de 6 a 10 , os materiais sedimentáveis deve ter um limite de $20 \mathrm{ml} / \mathrm{L}$; Ausência de solventes, gasolina, óleos leves e substâncias explosivas ou inflamáveis em geral; Ausência de despejos que causem ou possam causar obstrução das canalizações ou qualquer interferência na operação do sistema de esgotos; Ausência de qualquer substância em concentração potencialmente tóxica a processos biológicos de tratamento de esgotos; Ausência de óleo e graxas visíveis e concentração máxima 150 mg/l.

A 'Tabela 1' contém os parâmetros de concentrações de metais no chorume permitidos para o descarte, após o tratamento ( Decreto $\mathrm{N}^{\circ} 8.468$ no art 19-A).

Tabela 1: Parâmetros de concentrações de metais no chorume permitidos para descarte.

\begin{tabular}{lc} 
Concentrações máximas dos seguintes elementos & $\mathrm{Mg} / \mathrm{l}$ \\
\hline Arsênico, cádmio, chumbo, cobre, cromo hexavalente, mercúrio, prata e selênio & 1,5 \\
Cromo total e zinco & 5,0 \\
Estanho & 4,0 \\
Fenol & 5,0 \\
Ferro solúvel - (Fe2+) & 15,0 \\
Fluoreto & 10,0 \\
Sulfeto & 1,0 \\
Sulfato & 1.000
\end{tabular}

Fonte: Decreto $\mathrm{N}^{\circ} 8.468$ no art 19-A. 
Este trabalho corresponde a pesquisa do processo do tratamento do resíduo sólido - chorume, o qual faz um levantamento das soluções para o tratamento do chorume; das soluções para o reaproveitamento dos dejetos obtidos no processo do tratamento, e destaca as leis que definem os limites para disposição na natureza do chorume.

\section{Tratamento do chorume como meio sustentável}

O processo de tratamento do chorume é amplamente enquadrado na questão ambiental de sustentabilidade, onde fornece um melhor reaproveitamento de águas e o cuidado no descarte do resíduo ao meio ambiente. O conceito de desenvolvimento sustentável é a vida em equilíbrio dentro de uma concepção técnica como os estágios vivenciais harmônicos inseridos em contextos de desenvolvimento sustentável, solidariedade, democracia e justiça social (NAIME, 2014).

Naime (NAIME, 2014) descreve um conjunto de aproximação para definir desenvolvimento sustentável que patrocina a vida em equilíbrio:

1. Para contribuir com nosso sustento, que junto com o restante da sociedade caracteriza a sustentabilidade, devemos participar e contribuindo com a construção de empreendimentos compatibilizados com os meios físico e biológico;

2. Agora não é mais boa prática recomendável, a análise do ciclo de vida do produto, a gestão compartilhada e a logística reversa implica em adotar conceitos de eco design sempre que forem aplicáveis;

3. Tem que haver necessariamente uso conservativo de recursos naturais, tanto matérias primas quanto recursos hídricos e energéticos;

4. Sempre que necessário executar rigoroso tratamento de efluentes líquidos de qualquer natureza, satisfatórias práticas de gestão de resíduos sólidos e adequados monitoramentos atmosféricos, todos estes procedimentos devem ser executados dentro dos melhores conceitos e padrões técnicos, atingindo elevados níveis de eficiência e eficácia;

5. Uma postura de gestão ambiental e práticas de sustentabilidade proativas exige ações de educação ambiental sistêmicas e projetos comunitários de finalidade ambiental relevantes;

6. Disposição e comprometimento social com a transparência, a solidariedade, a democracia e a justiça social.

\section{Processos de tratamento do resíduo}

Os trabalhos sobre chorume apresentados na literatura ressaltam que as características, como a idade do aterro, têm influência significativa na composição química do chorume e consequentemente em sua tratabilidade. Portanto, a escolha entre as diversas alternativas de tratamento depende de parâmetros técnicos e econômicos (HUANG, 1993).

A seguir são descritas algumas das técnicas mais utilizadas relatadas na literatura para o tratamento de chorume:

\section{Precipitação Química}

“A precipitação química visa à remoção de compostos orgânicos não biodegradáveis, nitrogênio amoniacal e metais pesados. Esse método envolve a adição de produtos químicos que promovem a remoção de substâncias dissolvidas e suspensas por sedimentação. O método de precipitação química usualmente utiliza como precipitantes químicos: fosfato de amônia e magnésio ou estruvita, também conhecido com PAM, e hidróxido de cálcio ou cal hidratada, dependendo do alvo de remoção.”(TAVARES, 2011)

O diagrama de Pourbaix 'Figura 1' pode ser interpretado como um diagrama de fases, ele relaciona o potencial de eletrodo de um dado metal com o $\mathrm{pH}$ do meio, com as regiões de estabilidade das diferentes formas de se encontrar o metal. $\mathrm{O}$ pH inertiliza o metal, deixando próprio ao descarte. 
Figura 1: Diagrama de Pourbaix pra o metal cromo

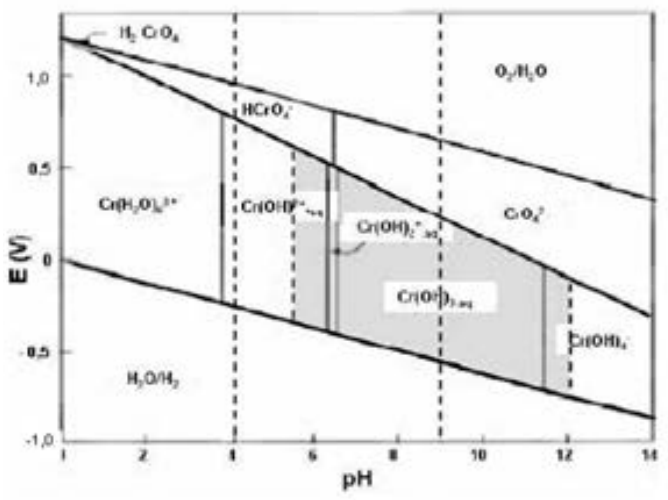

Fonte: Frois (2010)

\section{Coagulação/ Floculação}

"O processo de coagulação desestabiliza as partículas coloidais pela ação de um agente coagulante e é empregado imediatamente antes do processo de floculação, que promove a aglomeração dessas partículas através de agitação suave, porém completa, para facilitar o contato dos flocos uns com os outros, formando flocos maiores, mais suscetíveis à sedimentação. Os principais fatores relacionados ao processo são: a natureza química do coagulante, o pH e as condições (velocidade e tempo de mistura) de coagulação e floculação. O sulfato de alumínio tem sido o coagulante mais utilizado no tratamento dos chorumes, mas existem outros que também podem ser utilizados, tais como o sulfato ferroso, o sulfato férrico e o aluminato de sódio.”(TAVARES, 2011)

\section{Processos Oxidativos Avançados}

Segundo Silva ( SILVA, 2002) os processos oxidativos avançados (POA) envolvem a geração de radicais hidroxila $(\mathrm{OH})$, altamente reativos, que têm a capacidade de destruição total de muitos poluentes orgânicos. Para produzir esses ânions são utilizados oxidantes fortes como o ozônio e o peróxido de hidrogênio.

Os POAs formam como subprodutos o dióxido de carbono, água e ânions inorgânicos. Vantagens do processo incluem o alto potencial de oxidação, a remoção de sólidos dissolvidos, ferro e manganês, e a mineralização completa dos poluentes. (BAHÉ, 2008).

\section{Adsorção por Carvão Ativado}

A adsorção é um fenômeno de superfície no qual ocorre transferência de massa: uma substância é transferida da fase líquida para a fase sólida, permanecendo ligada por interações físicas ou químicas. Esse processo pode ser reversível ou irreversível e está relacionado à área disponível do adsorvente, à relação entre massa do adsorvido e massa do adsorvente, $\mathrm{pH}$, temperatura, forças iônicas e natureza química do adsorvente e do adsorvido. Devido à grande área de superfície, estruturas dos micro poros e alta capacidade de adsorção e reatividade, a adsorção por meio do emprego de carvão ativado granular (CAG) e carvão ativado em pó (CAP) vêm sendo largamente empregada na remoção de poluentes orgânicos e inorgânicos dos chorumes (GOMES, 2009).

\section{Sistemas de Lagoas}

São lagoas naturais ou artificiais preparadas para receber efluentes orgânicos. A degradação dos poluentes orgânicos é feita pelos microrganismos presentes na lagoa. As reações de degradação podem ser aeróbias (dependentes de oxigênio), anaeróbias (ocorrem sem a presença de oxigênio) ou uma combinação das duas. Sistemas de lagoas são projetados para realizar a melhor combinação possível de reações. A luz solar e a temperatura são parâmetros determinantes para a regulação das lagoas, fazendo com que elas sejam mais eficientes em climas tropicais e subtropicais (BAHÉ, 2008; GOMES 2009). 


\section{Filtros Biológicos}

São reatores preenchidos com material inerte (pedras, peças de plástico...) que serve de base para o lodo biológico se fixar. A biomassa aderida é composta de microrganismos que degradam a matéria orgânica do efluente que passa pelo reator. Da mesma forma que as lagoas, os filtros biológicos são classificados em aeróbios (necessitam de aeração) e anaeróbios. São costumeiramente utilizados em tratamento de esgotos (BAHÉ, 2008; GOMES, 2009).

\section{Evaporação}

A evaporação do chorume permite elevada redução de seu volume. Para realizar o processo pode-se fazer uso da energia solar, o que caracteriza uma evaporação natural, ou a queima do gás do aterro, o que caracteriza uma evaporação forçada.

A tecnologia de evaporação tem baixo custo de implantação e é de fácil manutenção. A evaporação natural se aplica a regiões de altos índices de insolação (regiões tropicais e subtropicais, por exemplo) e a evaporação forçada possibilita, ainda, a geração de créditos de carbono, fatores que estimularam o emprego de evaporadores convencionais em alguns aterros no Brasil (São Paulo, Bahia e Rio de Janeiro) (GOMES, 2009).

\section{Maneiras de reaproveitar o chorume:}

Durante o processo de tratamento do chorume pode-se de forma sustentável utilizar o biogás produzido, como também o lodo sedimentado pode ser utilizado para fins da agricultura ou industriais, e a água pode ser encaminhada ao reuso. A seguir algumas maneiras de reaproveitar os resíduos do processo de tratamento do chorume.

\section{Produção de biogás do aterro}

A formação e a taxa de geração dos principais constituintes do gás do chorume é variável ao longo do tempo e segue várias fases distintas, que foram descritas por Pavan (PAVAN apud TCHOBANOGLOUS,1993):

Fase I (ajuste inicial): a decomposição biológica da matéria orgânica ocorre principalmente em condições aeróbias devido à presença de certa quantidade de ar no interior do chorume.

Fase II (transição): a quantidade de oxigênio decai e as reações anaeróbias se desenvolvem. Os microrganismos responsáveis pela conversão da matéria orgânica em metano e dióxido de carbono iniciam a conversão do material orgânico complexo em ácidos orgânicos e outros produtos intermediários. Nesta fase, o $\mathrm{pH}$ do chorume começa a cair devido à presença de ácidos orgânicos e pelo efeito das elevadas concentrações de $\mathrm{CO}_{2}$ dentro do aterro;

Fase III (ácida): as reações iniciadas na fase de transição são aceleradas com a produção de quantidades significativas de ácidos orgânicos e quantidades menores de gás hidrogênio. O dióxido de carbono é o principal gás gerado durante esta fase e os microrganismos envolvidos nesta conversão, descritos como não metanogênicos, são constituídos por bactérias anaeróbias estritas e facultativas. As demandas bioquímica (DBO) 4 e química de oxigênio (DQO) 5 e a condutividade do chorume aumentam significativamente durante esta fase devido à dissolução de ácidos orgânicos no chorume. Também devido ao baixo pH, constituintes inorgânicos como os metais pesados serão solubilizados;

Fase IV (metanogênica): nesta fase predominam microrganismos estritamente anaeróbios, denominados metanogênicos, que convertem ácido acético e gás hidrogênio em $\mathrm{CH}_{4} \mathrm{e} \mathrm{CO}_{2}$. A formação do metano e dos ácidos prossegue simultaneamente, embora a taxa de formação dos ácidos seja reduzida consideravelmente. $\mathrm{O} \mathrm{pH}$ do chorume nesta fase tende ao meio mais básico, na faixa de 6,8 a 8,0;

Fase V (maturação): Esta fase ocorre após grande quantidade do material orgânico ter sido biodegradado e convertido em $\mathrm{CH}_{4}$ e $\mathrm{CO}_{2}$ durante a fase metanogênica. Como a umidade continua a migrar pela massa de resíduos, porções de material biodegradável ainda não convertidos acabam reagindo. A taxa de geração do gás diminui consideravelmente, pois a maioria dos nutrientes disponíveis foi consumida nas fases anteriores e os substratos que restam no chorume são de degradação lenta. 
Logo pode-se observar que o maior rendimento na produção do biogás são nas fases I, II, III. Na 'Figura 2' é representado a produção de gás de um aterro sanitário com alto índice de chorume.

Figura 2 :Fases do processo da produção de gás no chorume

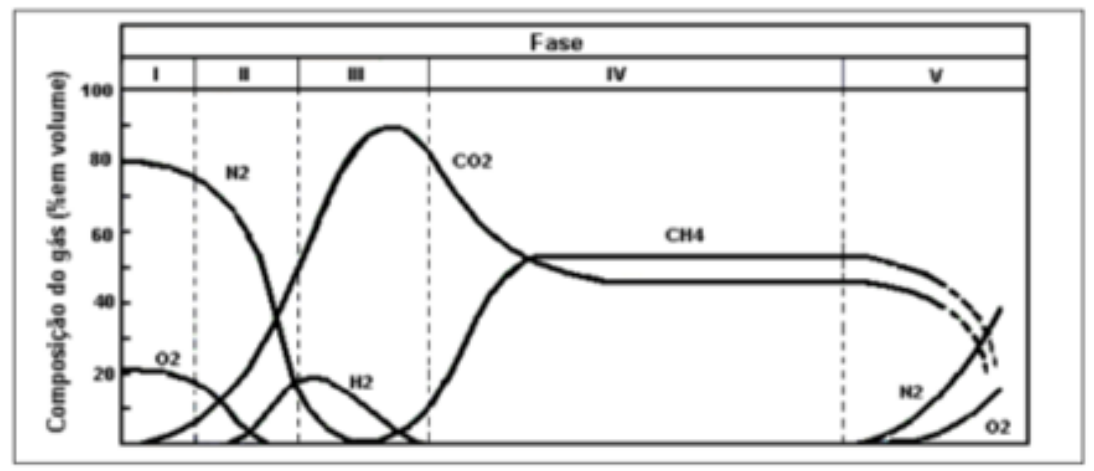

Fonte: PAVAN apud TCHOBANOGLOUS (1993)

Existem diversas tecnologias para efetuar a conversão energética do biogás. Entende-se por conversão energética, o processo que transforma um tipo de energia em outro. No caso do biogás, a energia química contida em suas moléculas é convertida em energia mecânica por um processo de combustão controlada. Essa energia mecânica ativa um gerador que a converte em energia elétrica. $\mathrm{O}$ ciclo Rankini (caldeira com turbina a vapor) e os motores de combustão interna do tipo "Ciclo - Otto" são as tecnologias .

\section{Produção de créditos de carbono}

No tratamento por evaporação pode ser liberado os gases na atmosfera ou captado, essa captação gera Créditos de carbono. Uma tonelada de dióxido de carbono (CO2) corresponde a um crédito de carbono. Este crédito pode ser negociado no mercado internacional.

Comprar créditos de carbono no mercado corresponde aproximadamente a comprar uma permissão para emitir GEE-gases de efeito estufa. O preço dessa permissão, negociado no mercado, deve ser necessariamente inferior ao da multa que o emissor deveria pagar ao poder público, por emitir GEE. Para o emissor, portanto, comprar créditos de carbono no mercado significa, na prática, obter um desconto sobre a multa devida. Cada crédito corresponde a 7,5 euros (25 reais),e é um mercado que movimenta 46 bilhoes(148 bilhoes de reais) de euro por ano.

\section{Produção de adubo}

Na etapa de decantação do processo de tratamento do chorume, onde adiciona-se agentes alcalinos (hidróxido de cálcio, de sódio, de amônio, óxido de magnésio, bicarbonato de sódio) para a precipitação dos metais e demais componentes sólidos, ocorre a formação do lodo. O lodo é encaminhado ao leito de secagem, centrifuga, filtro de prensa, após este tratamento ele pode ser reutilizado como adubo.

O CONOMA 375 é fundamentado no direcionamento e uso do lodo proveniente de tratamento de esgoto, esta Resolução veta a utilização agrícola de:

I - lodo de estação de tratamento de efluentes de instalações hospitalares;

II - lodo de estação de tratamento de efluentes de portos e aeroportos;

III - resíduos de gradeamento;

IV - resíduos de desarenador;

V - material lipídico sobrenadante de decantadores primários, das caixas de gordura e dos reatores anaeróbicos; 
VI - lodos provenientes de sistema de tratamento individual, coletados por veículos, antes de seu tratamento por uma estação de tratamento de esgoto;

VII - lodo de esgoto não estabilizado;

VIII - lodos classificados como perigosos de acordo com as normas brasileiras vigentes

Resultados de pesquisas da aplicação do lodo de esgoto em solos evidenciam aumentos na absorção de nutrientes pelas culturas com reflexos na produtividade, que pode ser igual e, em alguns casos, superior à adubação. Na produção do girassol, quando aplicado o lodo do esgoto em quantidade suficiente para fornecer o $\mathrm{N}$ exigido pela cultura do girassol, gera produtividade de sementes equivalente à obtida com a adubação mineral (LOBO \& GRASSI FILHO, 2007).

A aplicação do lodo na agricultura parece ser a forma mais difundida de utilização do resíduo. No entanto, outras formas de aproveitamento também estão sendo estudadas, a seguir na tabela 2:

Tabela 2: Formas de reaproveitamento do lodo do processo de tratamento do chorume

\begin{tabular}{ll}
\hline \multicolumn{1}{c}{ Reaproveitamento Industrial } & \multicolumn{1}{c}{ Reaproveitamento Agrícola } \\
\hline - Fabricação de tijolos e cerâmicas; & - Fertilizante orgânico e compostagem; \\
- Produção de agregado leve para construção civil & - Recuperação de solos degradados. \\
(as areias, pequenas pedras, etc.); & \\
- Produção de cimento. &
\end{tabular}

\section{Reuso da água}

Nos processos de reuso, variadas técnicas são utilizadas visando a remoção de resíduos e, dentre elas, podem ser citadas as de ordem física, como peneiramento e sedimentação e flotação, os processos biológicos, nos quais a remoção é efetuada por reações bioquímicas, realizadas por microrganismos, e também os processos físico-químicos, como: coagulação, floculação, decantação, filtração, adsorção por carvão, calagem e osmose reversa.

Aplicações da Água Reciclada: Irrigação paisagística: parques, cemitérios, campos de golfe, faixas de domínio de autoestradas, campus universitários, cinturões verdes, gramados residenciais; Irrigação de campos para cultivos: plantio de forrageiras, plantas fibrosas e de grãos, plantas alimentícias, viveiros de plantas ornamentais, proteção contra geadas; Usos industriais: refrigeração, alimentação de caldeiras, água de processamento; Recarga de aquíferos: recarga de aquíferos potáveis, controle de intrusão marinha, controle de recalques de subsolo; Usos urbanos não-potáveis: irrigação paisagística, combate ao fogo, descarga de vasos sanitários, sistemas de ar condicionado, lavagem de veículos, lavagem de ruas e pontos de ônibus, etc; Finalidades ambientais: aumento de vazão em cursos de água, aplicação em pântanos, terras alagadas, indústrias de pesca. Usos diversos: aquicultura, construções, controle de poeira.

\section{Considerações finais}

A escassez de recursos naturais despertou na sociedade a necessidade de cuidar, preservar e reciclar estes recursos. O tratamento do chorume é uma maneira sustentável de deter a poluição do meio ambiente, e em conjunto com o tratamento, o reaproveitamento.

As leis em destaque e as políticas do meio ambiente vêm tendo um amplo controle da geração de resíduos das empresas, fazendo assim com que o saneamento básico seja eficaz e mantenedor da preservação. 


\title{
Treatment process leachate and reuse
}

\begin{abstract}
:
With high pollutant content in its composition leachate stands out in your treatment based on the standards of solid waste environmental policies. These regulating the sewage rates and gas release into the atmosphere.

According to NBR No. 10.004, the Brazilian Association of Technical Standards - ABNT - "Waste in solid and semi-solid, resulting source community activities: industrial, domestic, hospital, commercial, agricultural, service and sweeping. They are included in this definition the sludge from water treatment systems, those generated in equipment and pollution control facilities as well as certain liquid whose characteristics make unfeasible its release in public sewers or water bodies, or to require that technically and economically unfeasible solutions, given to the best available technology. "
\end{abstract}

Leachate is the popular name given to the dark liquid generated in dumps or landfills, due to the percolation of rainwater through the waste mass. The environmental impact of this liquid is related mainly to the high concentration of organic matter in decomposition, which requires a large amount of oxygen taken from the environment that it reaches, or where it is released. The treatment of the slurry can be accomplished in a traditional manner by ETE (which includes gratings, lifting, sandbox, aerated lagoons, drying and sludge treatment), or by alternative means such as membrane separation; evaporation; oxidative treatments; activated charcoal; electrocoagulation, etc. The reuse of the slurry during the process is a focus on environmental sustainability, this paper will cover the generation of biogas, carbon credit, compost, reuse of water.

Treatment of leachate has the Sustainability as a shed, with a view to environmentally balanced system, which will serve society in a fair and economical way. The treatment of leachate will result in water recycling, sludge and gases, as well as in non-degradation of the environment, promoting meet the current needs of the population without compromising future generations.

\section{Keywords:}

Leachate; Treatment; Reuse; Sustainability. 


\section{Referências}

ROCCA, A., Parecer Técnico/ CETESB/ 004/ 11/ T sobre a Cava de Carapicuíba, São Paulo - SP, 2010 www.cetesb.sp.gov.br/;

NAIME, R., Sustentabilidade ambiental EcoDebate, 22/07/2014;

TAVARES, B.F.D., Tratamento de chorume: análise dos efluentes da evaporação forçada. Relatório de tcc Rio de Janeiro Março de 2011;

GOMES, L.P., Estudos de caracterização e tratabilidade de lixiviados de aterros sanitários para as condições brasileiras. PROSAB-Programa de Pesquisas em Saneamento básico. Resíduos Sólidos. Rio de Janeiro: ABES. 2009;

BAHÉ, F. Estudo da evaporação de lixiviados de aterros sanitários como alternativas técnologica de tratamento: testes em bancada. Dissertação (pós graduação em Eng. Civil)- UFPEPE, 2008;

LOBO, T. F.; GRASSI FILHO, H. Níveis de lodo de esgoto na produtividade do girassol. J ournal of Soil Science and Plant Nutricion, Valdivia, v.7, n.3, p.16-25, 2007;

PAVAN. M.C.O., Geração de energia a partir de resíduos sólidos urbanos: avaliação e diretrizes para tecnologias potencialmente aplicáveis no brasil. SÃO PAULO. 2010

FROIS, S.R., Utilização de Fases Minerais para Concentração e Especiação de Í ons Cr(III ) e Cr(V) . Dissertação de mestrado - Universidade Federal do Paraná, 2010

SI LVA, A.C., Tratamento do percolado de aterro sanitário e da toxicidade do efluente bruto e avaliação tratado. Rio de J aneiro, RJ - Brasil /J unho de 2002.

DECRETO N8.468 NO ART 19- DA LEI N. 997. A prevenção e o controle da poluição do meio ambiente. Brasil, 31 de maio de 1976.

CONOMA - Conselho Nacional do Meio Ambiente, Resolução $\mathbf{n}^{\circ} 375$ Critérios e procedimentos, para o uso agrícola de lodos de esgoto gerados em estações de tratamento de esgoto sanitário e seus produtos derivados. Brasil, 29 de agosto de 2006. 